Retraction

\title{
Retraction: Pavarin R.M. Alcohol Misuse Among Young Adults in Northern Italy. Safety 2019, 5, 31
}

\author{
Safety Editorial Office
}

MDPI, St. Alban-Anlage 66, 4052 Basel, Switzerland; safety@mdpi.com

Received: 23 December 2019; Accepted: 6 January 2020; Published: 7 January 2020

Since publication, we have investigated more closely the ethical procedures associated with the title article [1]. Research involve human participants typically requires ethical approval before it is carried out. Although surveys are exempt in some jurisdictions, for this paper our further investigations revealed concerns about how participants were recruited, whether they were informed that they were taking part in a piece of research, how and where the research was conducted, and about inclusion of survey questions related to the use of illegal substances.

The author confirmed that ethical approval was not requested for the research presented in [1] and we were unable to ascertain whether the local regulations for ethical approval were followed. The author was unwilling to retrospectively apply for ethical approval, and we did not receive a response from the author's university ethical board following enquiries about whether the study would be exempt from approval or whether they would be willing to provide approval.

The editorial board and editorial office consider the concerns sufficiently serious that we have decided to retract the paper. We regret that checks were not carried out more thoroughly prior to publication, however we are committed to upholding the highest ethical standards and protecting research participants. The journal has reviewed its handling of such cases. We note that the author did not agree to retraction of the article.

\section{Reference}

1. Pavarin, R.M. Alcohol Misuse among Young Adults in Northern Italy. Safety 2019, 5, 31. [CrossRef]

(C) 2020 by the author. Licensee MDPI, Basel, Switzerland. This article is an open access article distributed under the terms and conditions of the Creative Commons Attribution (CC BY) license (http://creativecommons.org/licenses/by/4.0/). 